Non-classical carbonium ions?

The Non-Classical Ion Problem. By Herbert C. Brown, with comments by Paul von R. Schleyer. Pp. 301. (Plenum: New York, 1977.) \$29.95.

THE non-classical carbonium ion is a formulation for an organic cation, no one structure for which, written with normal two-electron bonds, adequately describes the properties observed. One carbon atom (or more) is assigned a coordination number exceeding four, and some of the bonds are considered partial, and dotted; precise definition presents some difficulty. Proposed once in 1939, and freely in the 1950s, this concept came under rigorous scrutiny bythe Purdue school, who agreed that it was acceptable $a$ priori but asked whether it was needed, or whether the rapid interconversion of classical structures would explain observations more economically. An unusually vigorous controversy ensued, in which organic chemists not themselves involved have taken the opposed views, either that it was a sterile question attracting attention better directed elsewhere, or that it represented an important stage in the development of chemical theory, like the debate on tautomerism in about 1900. Documents published before mid-1965 were issued in reduced format, inter-related by a commentary by P. D. Bartlett, in 1966.

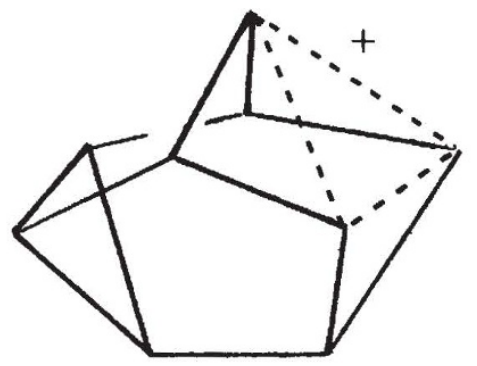

Now we have a full statment of the case for the prosecution, written in 1976-77 by H. C. Brown, with shorter comments by $\mathbf{P}$. von $\mathbf{R}$. Schleyer as advocate for the defence. Whatever else is said, the idea has encouraged non-classical formats in publication.

The subject is important, and this book is an excellent summary of the field. Much progress has been made. Brown's concept of equilibrating classical ions is now proved for many sys- tems, and some early views on steric effects are now undisputed. On the other hand, the phenonium ion, attacked by Brown in 1962, is now accepted, along with the knowledge that solvolysis reactions generally involve nucleophilic assistance from solvent (thanks largely to Schleyer). At last Brown can write of "Coate's cation" (see Figure): "the proposal that solvolysis proceeds throught the non-classical ion appears reasonable"; so the way is now open to agreement on effects to be expected from substituent and solvent changes in such species.

The debate is not over; even where Brown and Schleyer agree, the reader may decide to differ. He will, however, find this book readable and cogent throughout, and he will be able to move about it, checking points with the aid of a good index. He will be repeatedly reminded of the fundamental aims of organic chemistry. $\mathrm{He}$ will reach his own conclusions, and will probably end by deciding that the great controversy was worthwhile, after all.

M. C. Whiting

M. C. Whiting is Professor of Organic Chemistry at the University of Bristol, UK.

\section{Prostaglandin synthesis}

The Synthesis of Prostaglandins. By A. Mitra. Pp. 444. (Wiley: London and New York, 1977.) £16.90; \$28.60.

THE field of prostaglandin (PG) synthesis has received the attention of many organic chemists over the past decade, and as a result much novel and intriguing chemistry has been developed. Abhijit Mitra has set out to bring together, in this single review, the various synthetic strategies that have been used up to the middle of 1977, and to describe many intimate details of their execution.

Taken in order, the book begins with a brief, and at times misleading, description of PG biosynthesis; the unlikely implication that thromboxane $\mathrm{A}_{2}$ is partially converted to $\mathrm{PGE}_{2}$ and $\mathrm{PGF}_{2 \alpha}$ in vivo is an example. This minor blemish apart, chapters 2-15 describe the numerous approaches to the PGE and PGF systems in a very detailed manner. The individual syntheses are classified by the particular strategy used, such as that involving 1,4-addition to substituted cyclopentenones as the "fundamental" step, and that depending on the well known Corey lactone. This system works well, and renders the information readily accessible; however, it may be that a classification based on the historical development of such ingenious synthetic chemistry would have afforded the browsing reader with greater aesthetic rewards. Rather obscurely, one version of the synthesis of prostacyclin from $\mathrm{PGF}_{2 \alpha}$ lies buried in the chapter devoted to the Corey approach, together with a description, without references, of some prostacyclin analogues.

The remainder of the book is devoted to the synthesis of thromboxane $\mathbf{B}_{2}$, $\mathrm{PGA}_{2}, \mathrm{PGC}_{2}$, and finally, various $\mathrm{PG}$ analogues. This last chapter covers not only the very close relatives, such as 15-methyl-PGE 2 , but also some of the numerous heterocyclic and hetero-chain analogues that have been prepared; however, the complete lack of patent coverage, which is a significant drawback of the book as a work of reference, is very noticeable in this section. There are also some minor omissions from the published literature, such as the Upjohn ent-PGs, and the seco-PG analogues of Merck.

In summary, the book contains a very useful, if somewhat non-critical, review of the literature on PG synthesis, the coverage being generally quite comprehensive. For the synthetic chemist working in the field, the book will be an invaluable aid, with its clear and concise diagrammatic presentation and thorough indexing. For the non-specialist reader, there is described much elegant molecular architecture to be perused and enjoyed.

C. J. Harris

C. J. Harris is a research chemist at the Wellcome Foundation Research Laboratories, Beckenham, UK.

\section{Truelove Lowland, Devon Island, Canada: \\ A High Arctic Ecosystem}

edited by L.C. Bliss, PhD

This first ever study of an ecosystem in these northern islands summarizes 33 research projects conducted under the auspices of the International Biological Programme. The area studied covers 16 square miles with unusually rich flora and fauna. Data are presented for the basic scientific aspects of environmental and biological function, plus, uniquely, several aspects of lake biology, the carrying capacity of these lands for the Inuit, and the impact of petroleum exploration. This basic information may be applied to land management plans for other aretic islands.

735 pages, illustrated throughout, species lists, fold-out colored maps of soils and vegetation. $\$ 20$ (Canadian) plus $\$ 1$ packing and postage.

Edmonton, Alberta Canada T6G 2F.8 